\title{
HUBUNGAN POSISI KERJA DENGAN KELUHAN MUSKULOSKELETAL PADA UNIT PENGELASAN PT. X BEKASI
}

\author{
Rovanaya Nurhayuning Jalajuwita dan Indriati Paskarini \\ Departemen Keselamatan dan Kesehatan Kerja \\ Fakultas Kesehatan Masyarakat Universitas Airlangga \\ E-mail: rovanaya@yahoo.com
}

\begin{abstract}
This study was conducted to analyze the relation between body position with musculoskeletal complaints in welding unit of PT. X Bekasi. Welding is an important part of a steel fabrication company. Workers in the welding influenced by the position of work, the posture of their body of work and performance at work. Jobs that forced the labor to not an ergonomic posture when working cause workers had faster experience fatigue and indirectly provide additional workload. Health effects that arised as a result of an unergonomic worked postures are musculoskeletal disorders .This research is an observational research with cross sectional approach design. 32 workers were chosen as sample by using simple random sampling technique. Data were obtained by measuring, observing used Rapid Entire Body Assessment (REBA), and filling out questionnaire Nordic Body Map (NBM). Spearman rho correlation test was used to analyse the relation between variables. As many as $68.6 \%$ workers had a weak risk of having musculoskeletal disorder (REBA score of 4-7) and $62.5 \%$ workers had a weak level of musculoskeletal complaint. Based on the results of this study concluded that body position were significantly related to musculoskeletal complaints. There was a weak significant relationship between body position and musculoskeletal complaints $\left(p_{\text {value }}=0.005\right)$. It is suggested to companies that provide training on ergonomic working position when welding perform.
\end{abstract}

Keywords: Rapid Entire Body Assessment (REBA), Nordic Body Map (NBM), body position and musculoskeletal complaints

\begin{abstract}
ABSTRAK
Penelitian ini dilakukan untuk menganalisis hubungan antara posisi kerja dengan keluhan muskuloskeletal pada unit pengelasan PT. X, Bekasi. Proses pengelasan merupakan bagian penting dalam perusahaan yang bergerak dalam bidang fabrikasi dan konstruksi baja. Pekerja dalam melakukan pengelasan dipengaruhi oleh posisi kerja, postur kerja serta performa tubuh. Pekerjaan yang memaksa tenaga kerja untuk berada pada postur kerja yang tidak ergonomis menyebabkan pekerja lebih cepat mengalami kelelahan dan memberikan tambahan beban kerja. Dampak kesehatan yang muncul sebagai akibat dari postur kerja yang tidak ergonomis adalah keluhan muskuloskeletal. Penelitian ini merupakan jenis penelitian observasional dengan rancangan cross sectional. Sampel penelitian sebanyak 32 pekerja dengan menggunakan teknik simple random sampling. Data didapatkan dengan cara pengukuran, observasi menggunakan Rapid Entire Body Assessment (REBA) serta pengisian kuesioner Nordic Body Map (NBM) oleh pekerja pengelasan. Analisis hubungan menggunakan uji spearman. Sebanyak 68,6\% pekerja memiliki risiko muskuloskeletal sedang (skor REBA 4-7) dan 62,5\% pekerja pengelasan memiliki tingkat risiko keluhan muskuloskeletal sedang. Berdasarkan hasil penelitian dapat disimpulkan bahwa posisi kerja pekerja pengelasan memiliki hubungan yang signifikan dengan keluhan muskuloskeletal. Adanya hubungan yang signifikan $\left(p_{\text {value }}=0,005\right)$ pada posisi kerja dengan keluhan muskuloskeletal pekerja pengelasan, dengan tingkat hubungan menunjukkan korelasi sedang. Disarankan untuk memberikan training mengenai posisi kerja yang ergonomis ketika melakukan pengelasan.
\end{abstract}

Kata kunci: Rapid Entire Body Assessment (REBA), Nordic Body Map (NBM), posisi kerja dan keluhan muskuloskeletal

\section{PENDAHULUAN}

Banyaknya kebutuhan manusia mengenai bangunan, rancang bangun, serta transportasi yang harus terpenuhi, dan perkembangan zaman yang semakin maju maka menuntut manusia harus terus berkembang baik dalam pengetahuan, inovasi, maupun keahlian. Hal ini yang mendorong pesatnya angka perkembangan industri fabrikasi dan konstruksi baja di Indonesia setiap tahunnya. Meningkatnya perkembangan industri fabrikasi dan konstruksi baja mendorong semakin tingginya produktivitas yang diharapkan dapat memenuhi permintaan pasar. Ergonomi merupakan suatu disiplin ilmu yang terkait dengan interaksi antara 
manusia dengan unsur-unsur lain pada suatu sistem, dan profesi yang menerapkan teori, prinsip, metode, dan data untuk mendisain dalam rangka mengoptimalkan kenyamanan atau kesehatan manusia dan keseluruhan performa sistem (Santoso, 2013). Ergonomi juga merupakan suatu ilmu terapan yang menyelaraskan (fitting) stasiun kerja dan jenis pekerjaan dengan kapabilitas dari pekerja itu sendiri.

Tujuannya adalah untuk menurunkan tingkat risiko cedera dan meningkatkan motivasi dalam bekerja serta sekaligus meningkatkan produktivitas dari aktivitas pekerjaan dalam suatu stasiun kerja. Salah satu prinsip ergonomi sebagai salah satu acuan adalah sikap tubuh dalam pekerjaan sangat dipengaruhi oleh bentuk, susunan, ukuran serta penempatan mesin-mesin, penempatan alatalat petunjuk, dan cara-cara menggunakan mesin tersebut.

Studi yang dilakukan oleh Institute for Work and Health di Toronto menunjukkan bahwa penerapan aspek ergonomi dalam aktivitas pekerjaan akan meningkatkan kesehatan dan produktivitas kerja. Output dari penerapan aspek ergonomi tersebut adalah dapat memberi keuntungan ekonomis kepada perusahaan.

Di Negara Amerika Serikat yang merupakan negara maju dalam industri manufaktur telah mencatat bahwa WMSDs (work related musculoskeletal disorders) menjadi penyebab utama penyakit akibat kerja dan kehilangan 846.000 hari kerja setiap tahun dengan total biaya pengobatan yang dikeluarkan mencapai \$20 milliar sampai $\$ 43$ milliar (National Academy of Sciences dalam Humantech, 2003).

Hasil studi Departemen Kesehatan tentang profil masalah kesehatan di Indonesia tahun 2005 menunjukkan bahwa sekitar $40,5 \%$ penyakit yang diderita pekerja yang berhubungan dengan pekerjaannya. Menurut studi yang dilakukan terhadap 9.482 pekerja di 12 kabupaten/ kota di Indonesia, umumnya berupa penyakit muskuloskeletal (16\%), kardiovaskuler $(8 \%)$, gangguan syaraf $(6 \%)$, gangguan pernafasan $(3 \%)$ dan gangguan THT $(1,5 \%)$.

Keluhan muskuloskeletal adalah keluhan yang berada pada bagian otot skeletal atau otot rangka yang dirasakan oleh seseorang mulai dari keluhan sangat ringan hingga sangat sakit. Apabila otot menerima beban statis secara berulang dan dalam jangka waktu cukup lama maka akan dapat menyebabkan keluhan berupa kerusakan pada sendi, ligamen dan tendon. Faktor penyebab terjadinya keluhan muskuloskeletal adalah peregangan otot yang berlebihan, aktivitas berulang, sikap kerja tidak alamiah, penyebab sekunder dan penyebab kombinasi (Tarwaka, 2010).

Studi tentang muskuloskeletal pada berbagai jenis industri telah banyak dilakukan dan hasil studi menunjukkan bahwa bagian otot yang sering dikeluhkan adalah otot rangka yang meliputi otot leher, bahu, lengan, tangan, jari, punggung, pinggang, dan otot bagian bawah (Tarwaka, 2010). Dari berbagai macam penelitian tersebut dapat diketahui keluhan penyakit yang sering diderita oleh pekerja adalah WMSDs (work related musculoskeletal disorders), hal tersebut salah satunya dipengaruhi adanya posisi kerja. Posisi kerja mengacu pada bagaimana postur tubuh yang dilakukan, posisi kerja yang nyaman dan aman akan mempengaruhi produktivitas kerja yang lebih baik.

Pekerjaan yang memaksa tenaga kerja untuk berada pada postur kerja yang tidak ergonomis menyebabkan tenaga kerja lebih cepat mengalami kelelahan dan secara tidak langsung memberikan tambahan beban kerja. Penerapan posisi kerja yang ergonomis akan mengurangi beban kerja dan secara signifikan mampu mengurangi kelelahan atau masalah kesehatan yang berkaitan dengan postur kerja serta memberikan rasa nyaman kepada tenaga kerja terutama dalam pekerja yang monoton dan berlangsung lama, jika penerapan ergonomi tidak dapat terpenuhi akan menimbulkan ketidaknyamanan atau munculnya rasa sakit pada bagian tubuh tertentu. Salah satu dampak kesehatan yang muncul sebagai akibat dari postur kerja yang tidak ergonomis adalah musculoskeletal disorder (MSDs).

PT. X merupakan suatu perusahaan yang bergerak pada bidang fabrikasi dan konstruksi baja. Sumber bahaya dan risiko dalam hal keselamatan dan kesehatan kerja mempunyai peluang tinggi untuk dapat terjadi. Pekerjaan dalam bidang fabrikasi dan konstruksi baja dalam kesehariannya tidak lepas dari bantuan peralatan mesin, utamanya dalam unit pengelasan sangat diperlukan bantuan dari alat. Proses pengelasan merupakan suatu bagian penting yang ada pada perusahaan, dengan lama kerja lebih dari 8 jam per hari. Dalam kenyataannya banyak pekerja yang ditambah dengan jam lembur sampai dengan 12 jam per hari, dengan begitu peluang pekerja dalam keluhan MSDs sangatlah besar.

Pekerja dalam melakukan pengelasan sangat dipengaruhi oleh posisi kerja, postur kerja serta 
performa tubuh mereka saat bekerja. Performa seseorang secara ergonomis sama dengan keseimbangan antara tugas kerja dan kemampuan tubuh. Dengan adanya postur kerja yang ergonomis maka performa pekerja juga mengalami peningkatan. Tenaga kerja yang menjadi objek penelitian adalah pekerja pada unit pengelasan PT. X. Postur kerja dan posisi kerja yang tidak ergonomis berdampak pada menurunnya produktivitas kerja maupun performa kerja yang dapat mengakibatkan kecelakaan kerja, selain itu juga dapat mempengaruhi derajat kesehatan pekerja salah satunya adalah keluhan muskuloskeletal.

Tujuan dari penelitian ini adalah mempelajari hubungan posisi kerja dengan keluhan muskuloskeletal pada pekerja unit pengelasan di PT. X

\section{METODE}

Metode penelitian yang digunakan merupakan penelitian analitik. Berdasarkan pada jenis penelitiannya adalah observasional. Berdasarkan desain penelitian merupakan penelitian cross sectional karena variabel yang diteliti diamati pada satu waktu. Sampel penelitian sebanyak 32 pekerja dengan menggunakan teknik simple random sampling. Waktu penelitian dan pengambilan data dilakukan pada bulan november 2014 sampai dengan Juli 2015. Variabel yang diteliti adalah umur, lama kerja, posisi kerja, dan keluhan muskuloskeletal.

Data didapatkan dengan cara pengisisan kuesioner, wawancara dan observasi. Tenaga kerja diobservasi dengan mengamati postur tubuh dan selanjutnya menyesuaikan dengan lembar observasi Rapid Entire Body Assesment (REBA) kemudian dilanjutkan dengan wawancara untuk pengisian lembar Nordic Body Map (NBM) yang berguna dalam mengetahui tingkat keparahan keluhan muskuloskeletal responden. Instrumen yang digunakan yaitu kuesioner, lembar Nordic Body Map, lembar observasi penilaian REBA, dan kamera. Observasi dilakukan saat jam istirahat dengan tujuan agar pekerja tidak terganggu dalam aktivitas pekerjaannya. Data sekunder diperoleh dari data dan wawancara kepada staff Health, Safety and Environment perusahaan.

Data yang telah didapatkan selanjutnya diolah dalam beberapa tahapan guna mempermudah analisis data antara lain editing data, coding data, entry data, sorting data dan tabulating data. Editing data dilakukan dalam pengolahan data secara manual dengan cara memeriksa kelengkapan identitas responden serta instrumen pengisian data. Coding data dilakukan guna menyusun data yang telah didapatkan secara sistematis ke dalam bentuk yang mudah dibaca oleh aplikasi komputer. Setiap jawaban akan diubah dalam bentuk kode angka. Entering data yaitu memasukkan data yang telah diubah menjadi kode ke dalam komputer, selanjutnya data akan dianalisis menggunakan aplikasi dalam komputer. Sorting data digunakan untuk mengelompokkan jawaban berdasarkan jenisnya, dan tabulating data digunakan untuk menyajikan data dalam bentuk tabel yang sesuai dengan kebutuhan analisis dan untuk memudahkan peneliti.

Analisis data dilakukan secara analitik. Data yang didapatkan dari kuesioner, wawancara dan hasil pengukuran kemudian dianalisis dengan tabel, frekuensi, narasi, dan tabulasi silang guna mempermudah penyampaian hasil penelitian. Untuk mengetahui hubungan antar variabel menggunakan uji Spearman rho corellation dengan tingkat kemaknaan $\alpha=0,05$.

\section{HASIL}

Hasil penelitian yang terdiri dari umur, masa kerja, posisi kerja dan keluhan muskuloskeletal akan dijelaskan pada Tabel 1 .

Tabel 1. Distribusi Umur Pekerja di Unit Pengelasan PT. X Tahun 2015

\begin{tabular}{lcc}
\hline $\begin{array}{c}\text { Umur } \\
\text { (thn) }\end{array}$ & $\begin{array}{c}\text { Frekuensi } \\
\text { (n) }\end{array}$ & $\begin{array}{c}\text { Persentase } \\
(\%)\end{array}$ \\
\hline$<35$ & 20 & $62,5 \%$ \\
$\geq 35$ & 12 & $37,5 \%$ \\
\hline Total & 32 & $100 \%$ \\
\hline
\end{tabular}

Berdasarkan Tabel 1 dapat diketahui variabel umur terbagi menjadi 2 kelompok, yaitu kelompok umur kurang dari 35 tahun dan lebih dari sama dengan 35 tahun. Dari pembagian kelompok tersebut didapatkan bahwa sebagian besar $62.5 \%$ responden memiliki umur kurang dari 35 tahun dan 37.5\% memiliki umur lebih dari 35 tahun.

Tabel 2. Distribusi Lama Kerja Pekerja di Unit Pengelasan PT. X Tahun 2015

\begin{tabular}{lcc}
\hline $\begin{array}{c}\text { Lama Kerja } \\
\text { (jam) }\end{array}$ & $\begin{array}{c}\text { Frekuensi } \\
\text { (n) }\end{array}$ & $\begin{array}{c}\text { Persentase } \\
(\mathbf{\%})\end{array}$ \\
\hline$\leq \mathbf{8}$ & 4 & 12,5 \\
$>\mathbf{8}$ & 28 & 87,5 \\
\hline Total & 32 & 100 \\
\hline
\end{tabular}


Berdasarkan Tabel 2 dapat diketahui variabel lama kerja responden dikelompokkan berdasarkan 2 kategori yaitu kategori bekerja sampai dengan 8 jam dan kategori lama kerja lebih dari 8 jam. Berdasarkan pada hasil perhitungan didapatkan data bahwa sebagian besar $(87,5 \%)$ responden memiliki lama kerja lebih dari 8 jam per hari dengan ketentuan maksimal bekerja dari perusahaan selama 12 jam dalam setiap harinya.

Tabel 3. Distribusi Masa Kerja Pekerja di Unit Pengelasan PT. X Tahun 2015

\begin{tabular}{lcc}
\hline $\begin{array}{c}\text { Masa Kerja } \\
\text { (tahun) }\end{array}$ & $\begin{array}{c}\text { Frekuensi } \\
\text { (n) }\end{array}$ & $\begin{array}{c}\text { Persentase } \\
\text { (\%) }\end{array}$ \\
\hline$<\mathbf{1}$ & 3 & 9.4 \\
$\mathbf{1 - 5}$ & 23 & 71.9 \\
$>\mathbf{5}$ & 6 & 18.8 \\
\hline Total & 32 & 100 \\
\hline
\end{tabular}

Berdasarkan Tabel 3 dapat diketahui bahwa masa kerja responden dikategorikan dalam 3 kelompok, diantaranya masa kerja kurang dari 1 tahun, masa kerja 1 sampai dengan 5 tahun dan masa kerja lebih dari 5 tahun. Dari pembagian kategori tersebut didapatkan sebagian besar $(71,9 \%)$ responden memiliki masa kerja 1-5 tahun.

Penilaian posisi kerja terhadap postur tubuh responden menggunakan metode Rapid Entire Body Assessment (REBA). Metode REBA merupakan metode yang sangat sensitif dalam hal mengevaluasi risiko postur tubuh, khususnya pada sistem muskuloskeletal. Pembagian segmen tubuh juga dilakukan dalam metode ini. Segmen-segmen tubuh yang akan diberi kode secara individu serta mengevaluasi seluruh bagian anggota tubuh baik anggota badan bagian atas maupun badan, leher, dan kaki.

Penilaian dengan metode REBA didapatkan dari hasil pemberian skor kemudian dilakukan penentuan pada tabel grup A, grup B dan grup C. Pada hasil akhir yang didapatkan adalah menentukan tingkat

Tabel 4. Distribusi Tingkat Risiko menurut REBA Pekerja di Unit Pengelasan PT. X Tahun 2015

\begin{tabular}{lcc}
\hline \multicolumn{1}{c}{ Tingkat Risiko } & $\begin{array}{c}\text { Frekuensi } \\
\text { REBA }\end{array}$ & $\begin{array}{c}\text { Persentase } \\
(\mathbf{n})\end{array}$ \\
\hline Sedang & 22 & 68.6 \\
Tinggi & 9 & 28.1 \\
Sangat Tinggi & 1 & 3.1 \\
\hline Total & 32 & 100 \\
\hline
\end{tabular}

risiko cedera dengan menetapkan tingkat tindakan korektif yang diperlukan serta melakukan intervensi agar segera dilakukan perbaikan untuk mengurangi risiko yang ditimbulkan.

Berdasarkan tabel 4 dapat diketahui bahwa didapatkan sebagian besar $68,6 \%$ responden memiliki tingkat risiko menurut REBA sedang, $28.1 \%$ memiliki tingkat risiko menurut REBA tinggi dan 3.1\% memiliki tingkat risiko menurut REBA sangat tinggi.

Berikut ini merupakan beberapa contoh penilaian dalam menentukan tingkat risiko posisi kerja yang sering dilakukan oleh responden. Untuk risiko sedang dengan final score REBA 4-7 dapat diperhatikan pada Gambar 1.

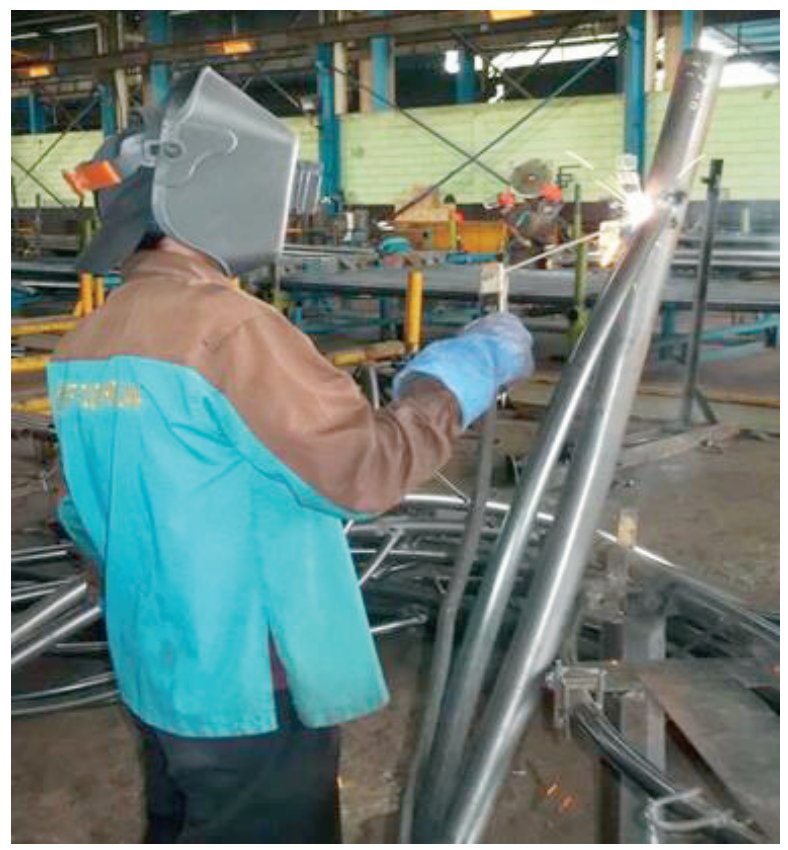

Gambar 1. Pekerjaan Pengelasan Kategori REBA Sedang.

Berdasarkan perhitungan REBA Gambar 1 dianalisis bahwa gerakan pada posisi badan normal diberikan skor 1, dikarenakan posisi badan bengkok maka ditambahkan skor perubahan berjumlah 1 . Untuk pemberian skor pada badan didapatkan skor 2. Posisi leher berada pada fleksi $0^{\circ}-20^{\circ}$ sehingga mendapatkan skor 1 dengan penambahan skor perubahan sebanyak 1 karena posisinya bengkok maka didapatkan skor leher 3. Penilaian skor pada kaki didapatkan skor 1 karena posisi responden berada pada posisi kedua kaki tertopang dengan baik di lantai. Hasil yang didapatkan dari penilaian 
badan, leher dan kaki selanjutnya dikonversikan ke dalam Group A dan menghasilkan skor 3.

Pada lengan bagian atas diperoleh skor 2 karena berada pada posisi antara $0^{\circ}-20^{\circ} \mathrm{ke}$ arah depan dengan posisi bahu naik maka ditambahkan adanya skor perubahan berjumlah 1. Posisi lengan bawah berada pada skor 1 karena berada pada posisi lengan bawah ke arah depan $60^{\circ}-100^{\circ}$. Pada pergelangan tangan memiliki skor 1 karena posisi pergelangan tangan $>15^{\circ}$ ke atas dan ke bawah. Hasil dari penilaian lengan atas, lengan bawah dan pergelangan tangan dikonversikan menjadi Group B dengan menghasilkan skor 2 .

Skor yang didapatkan dari Group A ditambahkan dengan skor 0 untuk beban yang diangkat $<5 \mathrm{~kg}$, Skor A menjadi 3. Group B ditambahkan dengan skor untuk jenis pegangan berjumlah 1 karena merupakan pegangan sedang yang berarti pegangan tangan dapat diterima tetapi tidak ideal, Skor B menjadi 3. Skor A dan Skor B kemudian dikonversikan ke dalam tabel $\mathrm{C}$ dan menghasilkan skor 3. Pada tahap akhir skor tabel $\mathrm{C}$ ditambahkan dengan skor jenis aktivitas otot satu atau lebih bagian tubuh dalam keadaan statis berjumlah 1 dan didapatkan final skor REBA menjadi 4 yang tergolong pada tingkat risiko sedang serta diperlukan tindakan perbaikan postur kerja agar dapat memperkecil serta mencegah terjadinya keluhan muskuloskeletal yang lebih tinggi pada pekerja.

Untuk penilaian risiko tinggi dalam REBA dengan final score REBA 8-10 dapat diperhatikan pada Gambar 2.

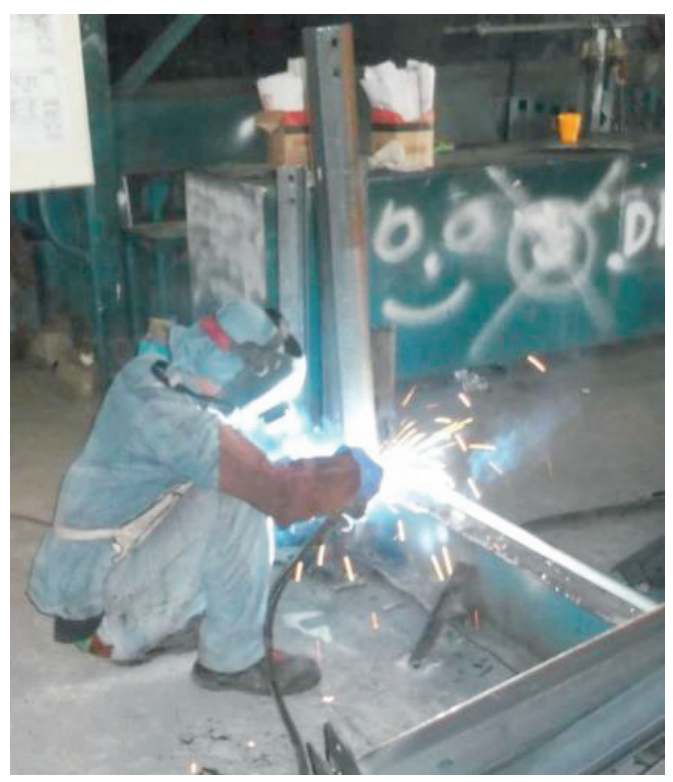

Gambar 2. Pekerjaan Pengelasan Kategori REBA Tinggi.
Berdasarkan perhitungan REBA Gambar 2 dianalisis bahwa gerakan pada posisi badan ke depan $0^{\circ}-20^{\circ}$ diberikan skor 2 , dikarenakan posisi badan bengkok maka ditambahkan skor perubahan berjumlah 1 . Untuk pemberian skor pada badan didapatkan skor 3. Posisi leher berada pada $>20^{\circ}$ ke arah depan sehingga mendapatkan skor 2 dengan penambahan skor perubahan sebanyak 1 karena posisinya bengkok maka didapatkan skor leher 3. Penilaian skor pada kaki didapatkan skor 1 karena posisi responden berada pada posisi kedua kaki tertopang dengan baik di lantai. Dikarenakan responden jongkok (kedua kaki ditekuk $>60^{\circ}$ ) maka ditambahkan skor perubahan 2 maka total skor pada kaki sebanyak 3. Hasil yang didapatkan dari penilaian badan, leher dan kaki selanjutnya dikonversikan ke dalam Group A dan menghasilkan skor 7.

Pada lengan bagian atas diperoleh skor 2 karena posisi lengan menyangga berat lengan maka diberikan skor perubahan berjumlah -1 . Total skor lengan atas berjumlah 1. Posisi lengan bawah berada pada skor 2 karena berada pada posisi lengan bawah ke arah depan $<60^{\circ}$ atau $>100^{\circ}$. Pada pergelangan tangan memiliki skor 2 karena posisi pergelangan tangan $>15^{\circ}$ ke atas dan ke bawah. Dengan adanya tambahan skor perubahan karena pergelangan tangan putaran menjauhi sisi tengah maka ditambahkan skor 1, jadi skor pergelangan tangan berjumlah 3 . Hasil dari penilaian lengan atas, lengan bawah dan pergelangan tangan dikonversikan menjadi Group B dengan menghasilkan skor 3 .

Skor yang didapatkan dari Group A ditambahkan dengan skor 1 untuk beban yang diangkat $5-10 \mathrm{~kg}$, Skor A menjadi 8. Group B ditambahkan dengan skor untuk jenis pegangan berjumlah 1 karena merupakan pegangan sedang yang berarti pegangan tangan dapat diterima tetapi tidak ideal, Skor B menjadi 4. Skor A dan Skor B kemudian dikonversikan ke dalam tabel $\mathrm{C}$ dan menghasilkan skor 9. Pada tahap akhir skor tabel $\mathrm{C}$ ditambahkan dengan skor jenis aktivitas otot satu atau lebih bagian tubuh dalam keadaan statis berjumlah 1 dan didapatkan final skor REBA menjadi 10 yang tergolong pada tingkat risiko tinggi serta diperlukan tindakan perbaikan postur kerja dengan segera agar dapat memperkecil serta mencegah terjadinya keluhan muskuloskeletal yang lebih tinggi pada pekerja.

Untuk penilaian risiko sangat tinggi dalam REBA dengan final score REBA 11-15 dapat diperhatikan pada gambar berikut: 


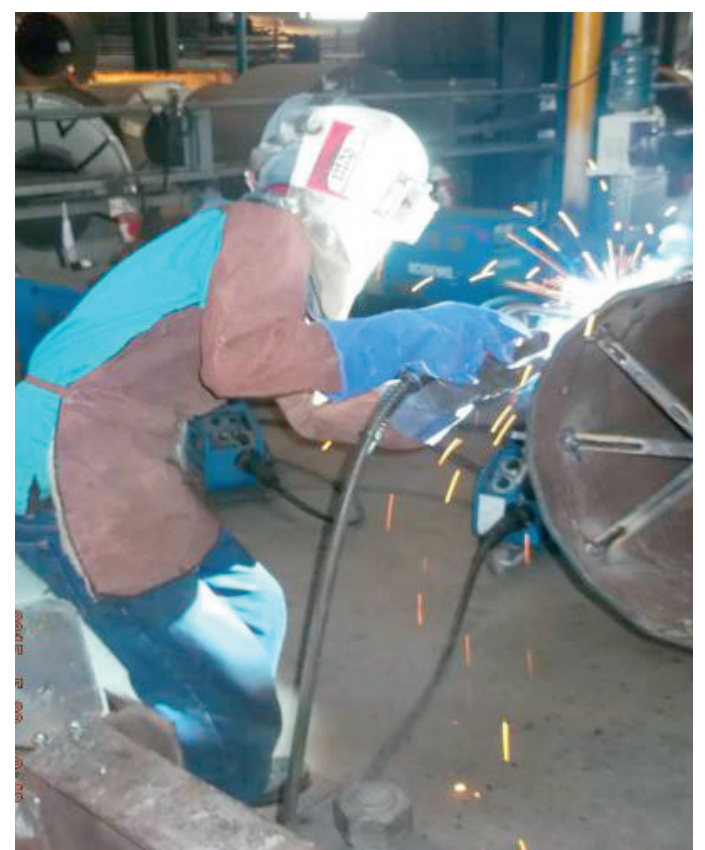

Gambar 3. Pekerjaan Pengelasan Kategori REBA Sangat Tinggi.

Berdasarkan perhitungan REBA Gambar 3 dianalisis bahwa gerakan pada posisi badan ke depan $20^{\circ}-60^{\circ}$ diberikan skor 3 , dikarenakan posisi badan bengkok maka ditambahkan skor perubahan berjumlah 1 . Untuk pemberian skor pada badan didapatkan skor 4. Posisi leher berada pada $0-20^{\circ}$ ke arah depan sehingga mendapatkan skor 1 dengan penambahan skor perubahan sebanyak 1 karena posisinya bengkok maka didapatkan skor leher 2 . Penilaian skor pada kaki didapatkan skor 2 karena salah satu kaki tidak tertopang di lantai dengan baik atau terangkat. Dikarenakan posisi lutut antara $30^{\circ}$ $60^{\circ}$ maka ditambahkan skor perubahan 1 maka total skor pada kaki sebanyak 3 . Hasil yang didapatkan dari penilaian badan, leher dan kaki selanjutnya dikonversikan ke dalam Group A dan menghasilkan skor 7.

Pada lengan bagian atas diperoleh skor 2 karena posisi lengan bengkok dan keadaan bahu naik maka ditambahkan skor 2. Total skor lengan atas berjumlah 4 . Posisi lengan bawah berada pada skor 1 karena berada pada posisi lengan bawah $60^{\circ}$ sampai $100^{\circ}$. Pada pergelangan tangan memiliki skor 2 karena posisi pergelangan tangan $>15^{\circ}$ ke atas dan ke bawah. Dengan adanya tambahan skor perubahan karena pergelangan tangan putaran menjauhi sisi tengah maka ditambahkan skor 1 , jadi skor pergelangan tangan berjumlah 3 . Hasil dari penilaian lengan atas, lengan bawah dan pergelangan tangan dikonversikan menjadi Group B dengan menghasilkan skor 5 .

Skor yang didapatkan dari Group A ditambahkan dengan skor 0 untuk beban yang diangkat $<5 \mathrm{~kg}$, Skor A menjadi 7. Group B tidak perlu ditambahkan dengan skor untuk jenis pegangan karena benda yang tergolong besar dan berat sehingga Skor B menjadi 5. Skor A dan Skor B kemudian dikonversikan ke dalam tabel $\mathrm{C}$ dan menghasilkan skor 9. Pada tahap akhir skor tabel $\mathrm{C}$ ditambahkan dengan skor jenis aktivitas otot satu atau lebih bagian tubuh dalam keadaan statis berjumlah skor 1, gerakan berulangulang terjadi lebih dari 4 kali salam satu menit berjumlah skor 1 , dan postur tubuh tidak stabil selama kerja berjumlah skor 1 maka didapatkan final skor REBA menjadi 12 yang tergolong pada tingkat risiko sangat tinggi serta diperlukan tindakan perbaikan postur kerja sesegera mungkin agar dapat memperkecil serta mencegah terjadinya keluhan muskuloskeletal yang lebih tinggi pada pekerja.

Penilaian keluhan Muskuloskeletal dalam penelitian ini menggunakan Nordic Body Map (NBM), dengan menggunakan ini dapat diketahui bagian-bagian otot yang mengalami keluhan dengan tingkat keluhan mulai dari rasa tidak sakit sampai sangat sakit. Dengan menganalisis peta tubuh maka dapat diestimasi jenis dan tingkat keluhan otot skeletal yang dirasakan pekerja.

Tabel 5. Distribusi Tingkat Keluhan Muskuloskeletal Pekerja di Unit Pengelasan PT. X Tahun 2015

\begin{tabular}{lcc}
\hline $\begin{array}{c}\text { Keluhan } \\
\text { Muskuloskeletal }\end{array}$ & $\begin{array}{c}\text { Frekuensi } \\
(\mathbf{n})\end{array}$ & $\begin{array}{c}\text { Perentase } \\
(\mathbf{\%})\end{array}$ \\
\hline Rendah & 8 & 25,0 \\
Sedang & 20 & 62,5 \\
Tinggi & 3 & 9,4 \\
Sangat Tinggi & 1 & 3,1 \\
\hline Total & 32 & 100 \\
\hline
\end{tabular}

Sebagian besar $62,5 \%$ pekerja memiliki keluhan muskuloskeletal dengan tingkat risiko sedang, 25\% pekerja memiliki keluhan muskuloskeletal dengan tingkat risiko rendah, 9,4\% pekerja memiliki keluhan muskuloskeletal dengan tingkat risiko tinggi, dan $3,1 \%$ pekerja memiliki keluhan muskuloskeletal dengan tingkat risiko sangat tinggi.

Hubungan antara posisi kerja dengan keluhan muskuloskeletal dapat dilihat pada tabel 6. Tabel 6 tersebut merupakan tabulasi silang antara variabel posisi kerja dengan variabel keluhan muskuloakeletal. Dari tabel tersebut dapat diketahui 
berapa banyak jumlah responden yang mengalami tingkat risiko REBA dengan adanya keluhan muskuloskeletal.

Tabel 6. Distribusi Tingkat Risiko REBA dengan Keluhan Muskuloskeletal Pekerja di Unit Pengelasan PT. X Tahun 2015

\begin{tabular}{|c|c|c|c|c|c|c|c|c|c|c|}
\hline \multirow{3}{*}{$\begin{array}{c}\text { Tingkat } \\
\text { Risiko } \\
\text { REBA }\end{array}$} & \multicolumn{8}{|c|}{$\begin{array}{l}\text { Tingkat Keluhan } \\
\text { Muskuloskeletal }\end{array}$} & \multirow{2}{*}{\multicolumn{2}{|c|}{ Total }} \\
\hline & \multicolumn{2}{|c|}{ Rendah } & \multicolumn{2}{|c|}{ Sedang } & \multicolumn{2}{|c|}{ Tinggi } & \multicolumn{2}{|c|}{$\begin{array}{c}\text { Sangat } \\
\text { Tinggi }\end{array}$} & & \\
\hline & n & $\%$ & $\mathbf{n}$ & $\%$ & n & $\%$ & $\mathbf{n}$ & $\%$ & $\mathrm{n}$ & $\%$ \\
\hline Sedang & 7 & 32 & 15 & 68 & 0 & 0 & 0 & 0 & 22 & 100 \\
\hline Tinggi & 1 & 11 & 5 & 56 & 3 & 33 & 0 & 0 & 6 & 100 \\
\hline $\begin{array}{l}\text { Sangat } \\
\text { Tinggi }\end{array}$ & 0 & 0 & 0 & 0 & 0 & 0 & 1 & 100 & 1 & 100 \\
\hline Total & 8 & 25 & 20 & 63 & 3 & 9 & 1 & 3 & 32 & 100 \\
\hline p value & & & & & & & & 0,00 & & \\
\hline
\end{tabular}

Berdasarkan Tabel 6 dapat diketahui bahwa sebanyak 15 orang (68\%) memiliki risiko postur kerja tingkat sedang dan mengalami keluhan muskuloskeletal tingkat sedang. Hasil uji statistik menggunakan Spearman's rho Correlation didapatkan $p$ value $=0,005$, karena $p$ value $<0,05$ maka terdapat hubungan antara posisi kerja dengan timbulnya keluhan muskuloskeletal pada pekerja di unit pengelasan.

\section{PEMBAHASAN}

Berdasarkan hasil penelitian dapat diketahui bahwa mayoritas responden berumur kurang dari 35 tahun dengan rentang usia antara 20 tahun sampai dengan 34 tahun. Umur mempunyai hubungan yang kuat dengan keluhan otot, terutama untuk otot leher dan bahu menurut Riihimaki et al (Tarwaka, 2010).

Chaffin dan Guo et al dalam Tarwaka (2010), menyatakan bahwa pada umumnya keluhan otot skeletal mulai dirasakan pada usia kerja, yaitu 25-65 tahun. Keluhan pertama biasanya dirasakan saat memasuki umur 35 tahun dan tingkat keluhan akan semakin meningkat seiring bertambahnya umur. Hal tersebut terjadi karena pada umur setengah baya, kekuatan dan ketahanan otot seseorang mulai menurun sehingga risiko untuk terjadinya keluhan otot meningkat.

Umur seseorang berbanding lurus dengan kapasitas fisik sampai batas tertentu dan mencapai puncaknya pada usia 25 tahun. Pada usia 50-60 tahun kekuatan otot menurun sebesar $25 \%$ serta kemampuan kerja fisik seseorang pada usia lebih dari
60 tahun menurun hingga 50\% dari usia seseorang yang berusia 25 tahun (Tarwaka, 2010).

Berdasarkan hasil penelitian terhadap lama kerja dapat diketahui bahwa mayoritas responden lebih sering bekerja selama 12 jam sehari, dengan jam kerja mulai dari pukul 08.00 sampai 21.00. Pada pukul 12.00 sampai dengan 13.00 merupakan jam istirahat bagi pekerja yang secara rutin dilakukan setiap harinya. Hari kerja dimulai dari hari senin sampai dengan sabtu yang berarti pekerja memiliki 6 hari kerja. Berdasarkan perhitungan lama kerja dalam sehari dikalikan dengan hari kerja dalam seminggu maka didapatkan lama kerja lebih dari 50 jam dalam seminggu.

Pada umumnya lama seseorang bekerja dalam sehari adalah 6-8 jam. Sisanya 16-18 jam merupakan waktu untuk kehidupan bersama keluarga dan masyarakat, istirahat, tidur, dan lainlain. Dalam seminggu, seseorang biasanya dapat bekerja dengan baik selama 40-50 jam (Suma'mur, 1996). Produktivitas seseorang mulai menurun sesudah 4 jam bekerja, keadaan ini dipengaruhi oleh menurunnya kadar gula yang ada dalam darah. Perlu adanya istirahat dan waktu makan yang bertujuan untuk meningkatkan kembali semangat dan konsentrasi diri. Maka dari itu istirahat setengah jam setelah bekerja selama 4 jam kerja secara terus menerus sangat memiliki arti penting dalam diri seseorang.

Namun pada penelitian yang telah dilakukan didapatkan data sebagian besar responden bekerja dengan jangka waktu lebih dari 8 jam sehari. Padahal dengan bekerja lebih dari 8 jam sehari sangat memungkinkan pekerja mengalami keluhan muskuloskeletal karena lama seseorang bekerja yang baik tidak lebih dari 8 jam sehari. Hal tersebut diperkuat dengan teori Suma'mur (1996) bahwa semakin panjang waktu kerja yang dihabiskan maka akan semakin besar pula kemungkinan terjadinya hal-hal yang tidak diinginkan.

Penelitian ini sejalan dengan yang dilakukan oleh Tyas Sistha (2013) pada petani tentang hubungan antara nyeri muskuloskeletal dengan kondisi stasiun kerja dan ukuran, serta posisi tubuh petani salah satunya adalah lama kerja yang menunjukkan bahwa terdapat hubungan antara lama kerja petani dengan keluhan muskuloskeletal.

Hasil penelitian postur tubuh dengan memperhatikan posisi kerja dalam penelitian dapat diketahui bahwa mayoritas pekerja pengelasan melakukan pekerjaan dengan kategori postur tubuh sedang dengan skor REBA berada di antara 4 sampai 
dengan 7. Posisi kerja pada pekerja pengelasan dapat diamati melalui bagaimana postur tubuh pekerja pada saat bekerja. Menurut kamus besar bahasa Indonesia postur tubuh adalah bentuk tubuh atau sikap badan yang terlihat dari ujung rambut sampai ujung kaki.

Posisi kerja yang biasa dilakukan oleh pekerja pengelasan adalah postur tubuh berdiri atau duduk dengan tumpuan dua kaki, posisi berdiri atau duduk dengan tumpuan satu kaki, badan membungkuk, badan membengkok, serta jongkok. Namun pada penelitian ini sebagian besar responden berada pada posisi kerja dengan postur tubuh berdiri di mana bertumpu pada satu kaki dengan membungkuk dan pengangkatan salah satu bahu. Selanjutnya untuk dapat mengetahui tingkat risiko muskuloskeletal pada postur tubuh saat bekerja yang memiliki keluhan msukuloskeletal dapat dilakukan dengan observasi menggunakan metode Rapid Entire Body Assessment (REBA).

Metode REBA merupakan suatu alat analisis postural yang sangat sensitif terhadap pekerjaan yang melibatkan perubahan mendadak dalam posisi, biasanya sebagai akibat dari penanganan yang tidak terduga (Tarwaka, 2010). Dalam penelitian ini tingkat risiko Muskuloskeletal pada proses pengelasan lebih tepat menggunakan metode REBA karena dalam metode REBA penentuan tingkat risiko tidak hanya dihitung dari postur tubuh atau posisi kerja saja melainkan juga ditambahkan dengan faktor-faktor yang dapat menambah risiko terjadinya Muskuloskeletal seperti penilaian tentang pegangan yang digunakan, dan juga aktivitas kerja yang dilakukan seorang tenaga kerja.

Berdasarkan hasil penelitian pada responden mengenai keluhan muskuloskeletal dapat diketahui bahwa mayoritas responden memiliki keluhan muskuloskeletal sedang. Keluhan muskuloskeletal adalah keluhan yang berada pada bagian otot skeletal atau otot rangka yang dirasakan oleh seseorang mulai dari keluhan sangat ringan hingga sangat sakit. Penilaian keluhan Muskuloskeletal dalam penelitian ini menggunakan Nordic Body Map (NBM), dengan menggunakan ini dapat diketahui bagian-bagian otot yang mengalami keluhan dengan tingkat keluhan mulai dari rasa tidak sakit sampai sangat sakit. Nordic Body Map meliputi 27 cara pembagian otot rangka pada kedua sisi tubuh kanan dan kiri. Dimulai dari bagian atas tubuh yaitu otot leher sampai dengan bagian paling bawah yaitu otot pada kaki. Melalui kuesioner Nordic Body Map maka akan dapat diketahui bagian otot mana saja yang mengalami keluhan atau nyeri.
Mekanisme penilaian yaitu kuesioner NBM dilakukan pengisian dengan skor yang telah dijelaskan diatas pada setiap bagian tubuh sisi kanan dan kiri kemudian keluhan yang dirasakan oleh responden akan mendapatkan skor 1 (tidak sakit), 2 (agak sakit), 3 (sakit) atau 4 (sangat sakit). Selanjutnya skor tersebut dijumlahkan seluruhnya sehingga didapatkan jumlah skor akhir dari keluhan yang telah dirasakan responden. Setelah didapatkan skor akhir NBM maka dapat diketahui tingkat risiko keluhan setiap responden. Dari penelitian ini mayoritas pekerja pengelasan memiliki keluhan muskuloskeletal kategori sedang dengan total skor individu 50 sampai dengan 70 .

Postur tubuh saat bekerja yang tidak ergonomis menjadi salah satu penyebab munculnya keluhan muskuloskeletal. Sebagian besar pekerja mengeluhkan adanya rasa nyeri pada bagian leher, punggung, paha dan kaki. Hal tersebut dapat terjadi karena posisi tubuh pada saat bekerja mayoritas bertumpu pada satu kaki dan jongkok yang terlalu lama, membungkuk dan posisi leher sering menghadap ke bawah dengan waktu yang lama.

Hasil penelitian mengenai hubungan umur dengan keluhan muskuloskeletal dapat diketahui bahwa mayoritas responden berumur kurang dari 35 tahun dengan keluhan muskuloskeletal sedang. Sedangkan keluhan muskuloskeletal tinggi dan sangat tinggi sebagian besar dialami oleh responden yang berusia lebih dari 35 tahun. Hasil uji statistik menunjukkan adanya hubungan antara umur dengan timbulnya keluhan muskuloskeletal pada pekerja pengelasan.

Hal ini sejalan dengan Tarwaka (2010), dan beberapa ahli lain yang menyebutkan bahwa pekerja yang memiliki umur kurang dari 35 tahun memiliki risiko kecil mengalami keluhan muskuloskeletal. Keluhan tersebut terjadi karena pada umumnya keluhan otot skeletal mulai dirasakan pada usia kerja, yaitu 25-65 tahun. Keluhan pertama biasanya dirasakan saat memasuki umur 35 tahun dan tingkat keluhan akan semakin meningkat seiring bertambahnya umur.

Umur seseorang berbanding lurus dengan kapasitas fisik sampai batas tertentu dan mencapai puncaknya pada usia 25 tahun. Pada usia 50-60 tahun kekuatan otot menurun sebesar $25 \%$ serta kemampuan kerja fisik seseorang pada usia lebih dari 60 tahun menurun hingga 50\% dari usia seseorang yang berusia 25 tahun (Tarwaka, 2010). Selain itu menurut Riihimaki et al dalam Tarwaka (2010), menjelaskan bahwa umur mempunyai hubungan 
yang kuat dengan keluhan otot, terutama untuk otot leher dan bahu.

Hasil penelitian mengenai hubungan lama kerja dengan adanya keluhan muskuloskeletal dapat diketahui bahwa mayoritas responden memiliki lama kerja lebih dari 8 jam dan keluhan muskuloskeletal sedang dalam satu hari kerja. Hasil uji statistik menunjukkan adanya hubungan yang kuat antara lama kerja dengan keluhan muskuloskeletal pekerja pengelasan. Dengan bekerja lebih dari 8 jam sehari sangat memungkinkan pekerja mengalami keluhan muskuloskeletal karena lama seseorang bekerja yang baik tidak lebih dari 8 jam sehari. Hal tersebut diperkuat dengan teori Suma'mur (1996), bahwa semakin panjang waktu kerja yang dihabiskan maka akan semakin besar pula kemungkinan terjadinya hal-hal yang tidak diinginkan.

Penelitian ini sejalan dengan yang dilakukan oleh Wijayanti (2013), pada petani tentang hubungan antara nyeri muskuloskeletal dengan kondisi stasiun kerja dan ukuran, serta posisi tubuh petani salah satunya adalah lama kerja yang menunjukkan bahwa terdapat hubungan antara lama kerja petani dengan keluhan muskuloskeletal.

Berdasarkan hasil penelitian pada tabel 3 dapat diketahui bahwa mayoritas pekerja yang bekerja selama 1-5 tahun mengalami keluhan muskuloskeletal sedang dengan hasil uji statistik menunjukkan terdapat hubungan yang kuat antara masa kerja dengan keluhan muskuloskeletal pada pekerja pengelasan.

Masa kerja dapat berhubungan dengan keluhan muskuloskeletal karena masa kerja dapat dikatakan sebagai faktor risiko dari suatu pekerja yang terkait dengan lama kerja. Hal tersebut didukung dengan seringnya pekerja memiliki lama kerja selama \pm 12 jam dalam sehari. Masa kerja merupakan waktu atau lama seseorang bekerja dihitung dari pertama masuk hingga saat penelitian berlangsung. Cohen et al dalam Tarwaka (2010), menjelaskan bahwa masa kerja memiliki hubungan yang kuat dengan keluhan otot dan meningkatkan risiko Muskuloskeletal. Keluhan muskuloskeletal merupakan penyakit kronis yang membutuhkan waktu lama dalam perkembangan dan manifestasinya.

Studi yang dilakukan Boshuizen et al dalam Margarini (2014), menyatakan bahwa seseorang yang bekerja lebih dari 5 tahun meningkatkan risiko terjadinya back pain dibandingkan kurang dari 5 tahun paparan. Hal ini dapat terjadi karena pembebanan tulang belakang dalam waktu yang lama dapat mengakibatkan rongga diskus menyempit secara permanen dan juga mengakibatkan degenerasi tulang belakang di mana dapat menyebabkan nyeri punggung bawah kronis.

Penelitian Zulfiqor (2010), menunjukkan adanya hubungan antara masa kerja dengan keluhan muskuloskeletal pada welder dengan nilai $\mathrm{P}$ value $=0.002$ di mana $\mathrm{P}$ value $<0.05$. Begitu juga yang dilakukan oleh Aisyah (2014), pada pekerja angkat-angkut tentang hubungan karakteristik individu dan posisi kerja dengan keluhan muskuloskeletal pada pekerja angkat-angkut di PT. AJG Gresik salah satunya mengenai masa kerja yang menunjukkan bahwa terdapat hubungan antara masa kerja dengan keluhan muskuloskeletal.

Hasil penelitian mengenai hubungan posisi kerja dengan adanya keluhan muskuloskeletal dapat diketahui bahwa mayoritas responden memiliki tingkat risiko postur tubuh menggunakan metode REBA tergolong sedang dengan tingkat keluhan muskuloskeletal sedang. Hasil uji statistik menunjukkan adanya hubungan yang kuat antara posisi kerja dengan adanya keluhan muskuloskeletal pada pekerja pengelasan.

Metode REBA merupakan suatu alat analisis postural yang sangat sensitif terhadap pekerjaan yang melibatkan perubahan mendadak dalam posisi, biasanya sebagai akibat dari penanganan yang tidak terduga (Tarwaka, 2010). Penerapan metode ini ditujukan untuk mencegah terjadinya risiko cedera yang berkaitan dengan posisi, terutama pada otototot skeletal.

Hal tersebut dapat terjadi karena postur tubuh yang tidak ergonomis. Kegiatan berulang merupakan salah satu penyebab terjadinya keluhan muskuloskeletal. Postur dan sikap tubuh merupakan salah satu faktor yang sangat penting untuk diperhatikan karena hasil produksi sangat dipengaruhi oleh apa yang dilakukan pekerja. Apabila postur tubuh pekerja tidak ergonomis maka efek yang ditimbulkan adalah pekerja akan cepat merasakan lelah sehingga konsentrasi, tingkat ketelitian menurun, pekerjaan menjadi lambat, kualitas dan kuantitas hasil produksi menurun. Dengan adanya penurunan tersebut pada akhirnya akan menyebabkan turunnya produktivitas (Santoso, 2004)

Penelitian ini sejalan dengan Ahmadi (2012) bahwa terdapat hubungan yang bermakna antara postur kerja dengan keluhan muskuloskeletal pada permanen kelap sawit ( $p$ value $=0,022$ ). Selain itu Hendra (2009) juga menemukan bahwa terdapat 
hubungan yang bermakna antara postur kerja dengan keluhan muskuloskeletal berdasarkan jenis pekerjaan pada pemanen kelapa sawit ( $p$ value $=0,013$ )

\section{SIMPULAN}

Adanya hubungan yang signifikan antara posisi kerja dengan keluhan muskuloskeletal pada pekerja pengelasan serta menunjukkan tingkat hubungan korelasi yang sedang.

Saran yang diberikan untuk perusahaan adalah pihak management mengevaluasi stasiun kerja yang biasa ditempati oleh pekerja pengelasan, kemudian mengadakan perombakan stasiun kerja guna memperkecil risiko keluhan muskuloskeletal selain itu juga bisa memberikan pelatihan atau training khusus mengenai pengelasan kepada pekerja pengelasan. Training berguna untuk menambah wawasan mengenai pekerjaan pengelasan, posisi kerja maupun postur tubuh yang ergonomis dalam pengelasan serta langkah-langkah yang tepat pada proses pengelasan guna mengurangi risiko keluhan muskuloskeletal.

\section{DAFTAR PUSTAKA}

Ahmadi, Hari. 2012. Analisis Sikap Tubuh dengan Keluhan Muskuloskeletal Pada Teknisi Mekanik dan Asisten Teknisi di TOTAL E\&P Indonesie. Skripsi. Surabaya: Fakultas Kesehatan Masyarakat Universitas Airlangga.

Aisyah, Fitri. 2014. Hubungan Karakteristik Individu dan Posisi Kerja dengan Keluhan Musculoskeletal Disorders pada Pekerja Angkat-Angkut di Pergudangan PT AJG Gresik 2014. Skripsi. Surabaya: Fakultas Kesehatan Masyarakat Universitas Airlangga.
Hendra. 2009. Risiko Ergonomi dan Keluhan Musculoskeletal Disorders (MSDs) Pada Pekerja Panen Kelapa Sawit. Prosiding Seminar Nasional Ergonomi IX Semarang.

Humantech. 2003. Applied Ergonomics Training Manual. Humantech Inc: Berkeley Australia.

Jalajuwita, Rovanaya Nurhayuning. 2015. Hubungan Karakteristik Individu dan Posisi Kerja dengan Keluhan Muskuloskeletal pada Pekerja Pengelasan PT. Duta Hita Jaya, Bekasi. Skripsi. Surabaya: Fakultas Kesehatan Masyarakat Universitas Airlangga.

Margarini, Ayu Fitriasih. 2014. Hubungan Faktor Karakteristik Individu, Faktor Ergonomis dengan Keluhan Subjektif Musculoskeletal Disorders (MSDs) pada Pekerja Konstruksi PT. X. Skripsi. Surabaya: Fakultas Kesehatan Masyarakat Universitas Airlangga.

Santoso, Gempur. 2004. Ergonomi Manusia, Peralatan dan Lingkungan. Jakarta: Prestasi Pustaka.

Suma'mur. 1996. Higiene Perusahaan dan Kesehatan Kerja (Hiperkes). Jakarta: Toko Gunung Agung.

Tarwaka. 2010. Ergonomi Industri, Dasar-Dasar Pengetahuan Ergonomi dan Aplikasi di Tempat Kerja. Penerbit: Harapan Press Solo.

Wijayanti, Tyas Sistha. 2013. Hubungan Antara Nyeri Muskuloskeletal dengan Kondisi Stasiun Kerja dan Ukuran, Serta Posisi Tubuh Petani. Jurnal Media AntroUnairDotNet Vol. 2 No. 2 Hal. 5.

Zulfiqor, Taufik M. 2010. Faktor-faktor yang Berhubungan dengan Keluhan Musculoskeletal Disorders pada Welder di Bagian Fabrikasi PT. Caterpillar Indonesia Tahun 2010. Skripsi. Jakarta: UIN. 